ARTICLE

DOI: $10.1057 / \mathrm{s} 41599-018-0094-8$

OPEN

\title{
Fear of crime: the impact of different distributions of victimisation
}

\author{
Rafael Prieto Curiel ${ }^{1} \&$ Steven Richard Bishop ${ }^{1}$
}

\begin{abstract}
There is often a mismatch between levels of crime and the fear of becoming a victim of crime. It is not uncommon to find individuals who suffer little or no crime but yet who are still fearful of some future crime. Alternatively, a place or region might see an increase in crime over time while the fear of crime remains unchanged. Building on a model that previously considered the fear of crime as an opinion shared by simulated individuals, here the impact that different distributions of crime have on the fear experienced by the population is analysed. Simulating the dynamics of the fear of individuals, along with changes of the distribution of crime, leads to results which show that fear is sensitive to the distribution of crime and that there is a phase transition for high levels of concentration of crime. A policy may be oriented to reduce crime, so that the population effectively suffers less crime, but if the victimisation is displaced to other individuals, then the perception of insecurity may not decrease, with fear becoming more widespread.
\end{abstract}

\footnotetext{
${ }^{1}$ University College London, Mathematics Department London, London WC1E 6BT, United Kingdom. Correspondence and requests for materials should be addressed to R.P.C. (email: rafael.prieto.13@ucl.ac.uk)
} 


\section{Introduction}

ear of crime emerges as a social phenomenon (Austin et al., 2002) which, in extreme cases, impinges on the quality of life (Jackson and Gray, 2010), causes paranoia, anxiety and other psychological issues on a personal level (Ruijsbroek et al., 2015) and, at a social level, causes prejudice and segregation so that this insecurity has now become a major policy concern (Carro et al., 2010). Fear of crime leads to those who are more prosperous to protect themselves and their property, possibly displacing crime to those less privileged (Box et al., 1988). Fear can also transform some public places into no-go areas (Morgan, 1978) which has a severe impact on the local prosperity.

Fear of crime depends on many factors, perhaps the most obvious being actual crime: at a micro level, it might be expected that people who suffer more crime also experience more fear and, at a macro level, that regions with a higher number of crimes are also considered to be less secure. However, this is rarely the case. At an individual scale, significant levels of fear are often reported by people who enjoy low levels of victimisation and, in general, many more people are fearful than are actually victimised (Skogan, 1987). Also, at a regional scale, places with less crime might be perceived as being less secure, and furthermore, fluctuations observed in the number of crimes suffered do not lead to increases or decreases in the general concerns of crime within a region (Prieto Curiel and Bishop, 2016b). Thus, observing the mismatch between crime and its fear and the relevance it has at a social and political level, warrants further investigations of the aspects which might affect the personal perception of crime, for instance, demographic factors (such as age or gender), regional factors (if it is a dark or crowded street) and others, such as the amount and style of media coverage of crime.

Previous analysis of the fear of crime has already produced important outcomes. For instance, women and older people tend to feel more insecure (Carro et al., 2010; Borooah and Carcach, 1997), ethnic minorities tend to be more fearful (Brunton-Smith and Sturgis, 2011) as well as poor people (Pantazis, 2000), and that having some familiarity with the area reduces concerns about suffering a crime (Gilchrist et al., 1998). One of the most frequently considered causes of the fear of crime is media. However, the audience of different media channels is self-selective (Lane and Meeker, 2003) and messages often depend on the interpretation of the consumer (Heath and Gilbert, 1996; Ditton et al., 2004), also, crime reported on the media is not a reflection of reality, with media placing more emphasis on violent crime (Chadee and Ditton, 2005), therefore, the impact of the media on the fear of crime is unclear (Hollis et al., 2017).

In terms of fear of crime, the most obvious cause is actually suffering a crime. There have been some quantitative results which show that past victimisation more than doubles the odds ratio of having fear of crime (Hale et al., 1994; Tseloni, 2007), while different types of crime have a different impact on fear (Skogan and Maxfield, 1981). However, since the majority of the population does not, in fact, suffer any crime (Prieto Curiel and Bishop, 2016b) fear of crime is thus the result of a more complex social dynamics which does involve the victims of crime but also involves other social aspects. Crime is, relatively speaking, a rare event (Tseloni et al., 2010) tending to be highly concentrated so that, unfortunately, a particular person, a business, or a street may suffer a much higher number of crimes than the others (Farrell and Pease, 1993; Farrell, 2015; Pease, 1998; Brantingham and Brantingham, 2010; Johnson, 2010). But the fact that crime is rare and highly concentrated also means that fear of crime is more frequent than crime itself (Grogger and Weatherford, 1995).

How then should the mismatch between crime and its fear be explained and how does the fear of crime emerge as a social phenomenon? Furthermore, how can policies be designed to tackle this complex social issue if it is not clearly understood? Having data or observations to validate the analysis would be ideal, however, at an individual scale, it is almost impossible to measure the impact that suffering a crime has compared to the impact of other aspects of fear (for instance, hearing that a neighbour suffered a crime as opposed to being the actual victim of that crime). Observations at an individual scale are typically based on victimisation surveys, which frequently do not track the fears of the same individuals over time. This said, there has been a study that does consider two cohorts of the same interviewees to determine changes in attitudes and concerns before and after suffering a crime (Skogan, 1987). But, for this type of study, only a small number of those interviewed were the victims of crime (5\% of personal crime and only 6 elderly people who suffered recent victimisation) since crime is infrequent. To generalise any result or pattern based on the experiences of only a few individuals is not sensible and, at individual scale, detecting any of the factors related to fear of crime is highly complicated, particularly if the person does not suffer any crime but is nonetheless fearful.

At a regional scale, having observed a mismatch between crime and its fear which is not clearly explained by aspects at individual scale, means that the emergence of a complex pattern can be observed, that arises as a result not just of crime, but also, due to the interactions of the individuals, with feedbacks and nonlinear effects in the process that need to be considered.

Crime itself is a complex phenomenon with unexpected social behaviours being seen which are difficult to understand, control and, sometimes, even to quantify (D'Orsogna and Perc, 2015; Helbing et al., 2015). For instance, it is natural to assume that by enforcing longer prison sentences, harder punishments or by increasing fines, less crime would be observed, but this is not usually true (Becker, 1968). It is perhaps expected that allocating more police reduces crime via deterrence, but this also might not be true (Kleck and Barnes, 2014) and in the case of fear of crime, it is frequently assumed that a city with fewer crimes experiences less fear, but again, results are often contradictory. Mathematical models of crime, thus, become powerful tools which help explain why this complex behaviour emerges. For instance, a mathematical model for the spatial concentration of crime was used to explain the emergence of criminal hotspot patterns (Short et al., 2010); another model showed that when there is significant levels of crime, the probability of being arrested goes down and so criminals create a safer environment for themselves to commit more crimes (Glaeser et al., 1995); while another model showed the importance of delivering police to scenes of riots before control is lost (Davies et al., 2013). A useful review which shows some of the weaknesses frequently encountered with traditional economic and statistical models can be found in the work of Mirta Gordon (Gordon, 2010) and a valuable review of some of the powerful mathematical models in crime science can be found in the work by Maria D'Orsogna and Matjaž Perc (2015).

In a recent development (Prieto Curiel and Bishop, 2017), a model for an individual's fear of crime was introduced, taking into account whether the person suffers a crime during a given time period, the impact of sharing their fear with others and having memory decay. This model showed that, under certain conditions, fear of crime might still be expected even when there is little or no crime, with this fear being the result of shared opinions rather than actually suffering a crime. Here the impact that the distribution of crime in the population has on the level of fear is investigated. In particular, the case of two populations, both with the same amount of crime but where in one case, the crime is highly concentrated (that is, only a few individuals actually experience possibly many crimes) while in the other, 
crime is evenly spread (that is, all individuals have the same probability of being the victim of a crime), is studied to determine whether they have a similar fear.

Having a model, which simplifies interactions of individuals and assumes certain properties and distributions, that is capable of reproducing the complex observed behaviour, gives us the ability to then have an idea of the impact that quantitative changes (such as a reduction of the crime rates) and qualitative changes (such as a different distribution of the same amount of crime) would have on the fear of crime.

\section{Mathematical model for the fear of crime}

Consider that the person $i$ has, at time $t$, a fear of crime expressed as a continuous variable $s_{i}(t) \in(0,1)$, where a value of $s_{i}(t)$ closer to one means that the individual experiences a higher fear and a value closer to zero means lower fear. Quantifying the individual fear of crime and reducing it into a single-valued number clearly has its disadvantages since it reduces a complex concept and perhaps simplifies relevant psychological and social factors. For instance, it does not distinguish whether the person is fearful because they walk home alone at night or because someone rings their doorbell while these two scenarios are clearly different (Farrall et al., 2000). However, quantifying fear following the described methodology does provide a useful ordering, so that $i$ is more fearful than $j$ when $s_{i}(t)>s_{j}(t)$, but also importantly, it provides a reference system to map social behaviours into quantifiable units.

A regional measure of fear (the fear from a city, a district or a specific group of individuals) is constructed, given simply by the average fear of the individuals $\bar{s}(t)$, which might then be used to compare between two different regions or the same region between different time periods.

There are many reasons why a person changes their fear of crime, leading to different quantitative values of $s_{i}(t)$ and $s_{i}(t+$ 1). Here, the unit of time $t=1$ is taken to be a week, and so, the question is what happens during 1 week which changes the individual fear of crime. Following the model for the dynamics of the fear of crime (Prieto Curiel and Bishop, 2017), an individual is considered to update their fear from time $t$ to $t+1$ for three reasons. Firstly, whether the person suffered a crime or not, secondly, whether the person has a social interaction or not and lastly, the impact of memory decay, each considered over the same time period. The impact that each of these three elements has is as follows:

Crime-if individual $i$ suffered a crime, their fear increases to $s_{i}(t+1)=1$ regardless of any previous perceptions. Although the impact of suffering different types of crime or the impact of being a victim for the first time could be considered, the model assumes that all crimes have the same impact on every victim.

Social Interaction-if individual $i$ interacts with individual $j$, then it is assumed that they share their fears and experiences and after their interaction, both individuals update their fear and reach a state closer to consensus. Thus, they update their fear by $s_{i}$ $(t+1)=s_{i}(t)-\mu\left(s_{i}(t)-s_{j}(t)\right)$ if $s_{i}(t)>s_{j}(t)$ and by $s_{i}(t+1)=s_{i}$ $(t)-v\left(s_{i}(t)-s_{j}(t)\right)$ if $s_{j}(t) \geq s_{i}(t)$. With $v>\mu$ it is implicitly assuming that a more fearful person has a more dominant opinion (Latané, 1981) so that the person with the highest fear of crime also has a bigger impact on the other individual and so, a contagion process for the fear of crime is being modelled (Gilchrist et al., 1998).

The causal mechanism suggested here are clearly a simplification of a complex reality. The concept of 'social interaction' incorporates, for the less fearful person, all indirect victimisation (for example, being the witness of a crime or sharing fears and experiences with others), whereas, for the more fearful person, the social interaction incorporates the impact and social support provided to victims of crime (and fearful people) and any help given to people affected by crime or traumatic events. Although it has been found that the effects of social support on fear of crime are small (and so the value of $\mu$ could be considered to be equal to zero) (Sacco, 1993) it takes into account the potential support given by the social interaction and the influences from victim support groups and other organisations.

Memory decay - a person updates their perception by a factor, so that $s_{i}(t+1)=\psi s_{i}(t)$, with $\psi<1$ which represents that the individual either forgives or forgets their past perceptions or experiences. Thus, if person $i$ does not suffer any crime and does not have any social interaction between $t=0$ and $t=n$, then their fear is expressed as $s_{i}(n)=\psi^{n} s_{i}(0)$, where $s_{i}(0)$ is their initial perception. Therefore, the assumption is that an individual who does not suffer any crime and does not have any social interaction, tends to perceive that their location is more secure as time goes by. The fact that the impact of most crimes decreases within a few weeks (Skogan, 1987) is the aspect considered by the model. Perhaps, although the causal mechanism is not clear, rather than losing memory, previous experiences are out to the back of our minds and do not recall it when factoring our fear of crime at a later time, but this goes beyond the scope of our study.

Although other elements could also be relevant, for instance, the influence of the media with crime-related news reported on the radio or the television or even social media, the impact that media has on the fear of crime is not clear and so other elements are not considered in the model. Also, the model considers all crimes to be the same whereas the victim of kidnap might have a different level of fear than a person whose wallet is stolen. Furthermore, the way in which fear is quantified, reducing a complex issue into a single number does provide useful answers in terms of why a mismatch between crime and fear of crime is observed. What is more, the model enables us to explain the reasons why a decrease in crime might not improve the perception of security of a region and the impact that different distributions and degrees of concentration of crime have on the generalised fear. Combining these three effects gives a reasonable description of the dynamics of the fear of crime.

\section{Establishing the victimisation profile}

It is assumed that the number of crimes that the person $i$ suffers during 1 week follows a Poisson distribution with rate $\lambda_{i} \geq 0$ and that the $N$ individuals from the population can be divided into $k$ separate groups such that each group has $N_{j}$ individuals who suffer the same rate $\lambda_{j}$, with $j=1,2, \ldots, k$. All individuals belong to a single group, so $N_{1}+N_{2}+\cdots+N_{k}=N$ and also, an assumption is that $\lambda_{j}<\lambda_{j+1}$, i.e., groups are considered in increasing order according to their crime rate. A plot of the (cumulative) size of the groups on the horizontal axis against their corresponding crime rate gives us the victimisation profile of the population (Prieto Curiel et al., 2017). Although it may seem a simplification of the crime distribution, this method of profiling has been used to measure the actual concentration of crime in a population (Prieto Curiel et al., 2017) and it does allow us to consider different distributions of crime in a population (by changing the corresponding rates $\lambda_{j}$ and sizes $N_{j}$ ) and also, it allows the expected departures from what might have expected if crime was simply a matter of chance to be considered. Finally, this mixture method gives us the ability to control the expected number of crimes suffered by the population, given by

$$
C=\sum N_{j} \lambda_{j}
$$




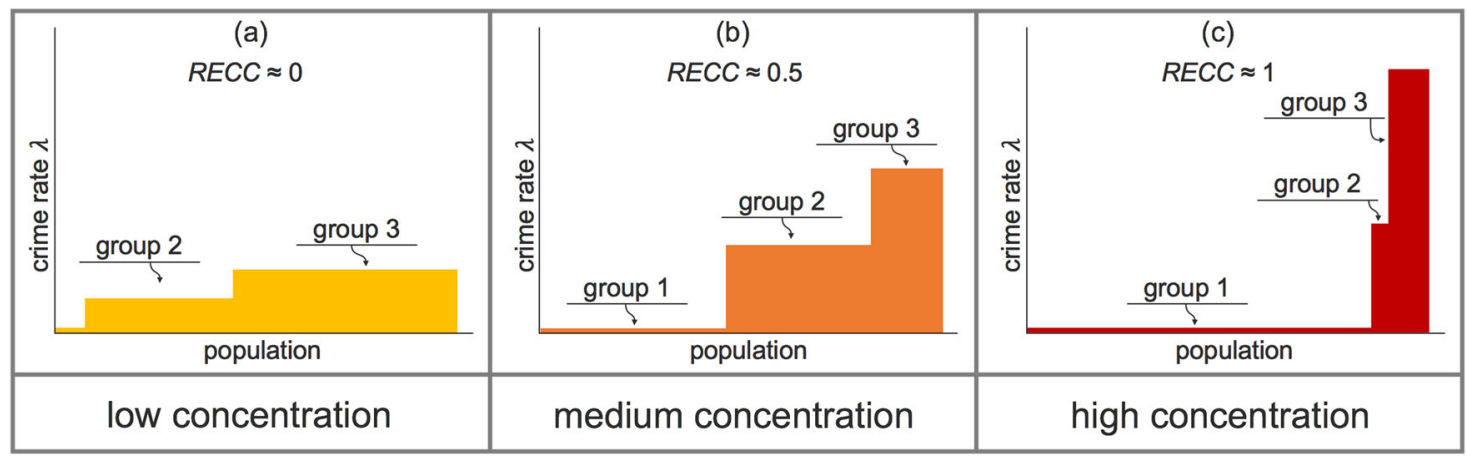

Fig. 1 Different degrees of concentration of crime. Panel (a) shows a low concentration of crime, observed when all individuals experience a similar crime rate $\lambda_{i}$ and therefore, the RECC is close to zero. Panel (b) has a medium concentration of crime and panel (c) shows a high concentration, observed when a small population group suffers a high crime rate and therefore, the RECC is close to one

Thus, the number of crimes suffered by the individuals can be simulated with various, different distributions such that their populations still expect the same number of crimes.

As a summary metric for the distribution of crimes, the Rare Event Concentration Coefficient (RECC) (Prieto Curiel and Bishop, 2016a) is used, which is computed as the Gini coefficient of the rates $\lambda_{j}$ and sizes $N_{j}$ (Dorfman, 1979), where a value of the RECC closer to zero means less concentration of crime and a value of the RECC closer to one means a higher concentration.

Different victimisation profiles. The objective here is to compare the impact of different distributions of crime and so populations are examined with various sizes of the groups $\left(N_{1}, N_{2}, \ldots, N_{k}\right)$ together with their corresponding rates $\left(\lambda_{1}, \lambda_{2}, \ldots, \lambda_{k}\right)$ taken into account. It is assumed that a group exists which does not suffer crime, referred to as the immune population group (Sparks, 1981; Hope and Trickett, 2008), so $\lambda_{1}=0$, where the size of this group $\left(N_{1}\right)$ may vary from a small number of individuals (even zero in the limit) to a large group containing almost all individuals within the population. Also, it is assumed that the (expected) number of crimes suffered by the population is fixed, so that $C=\sum N_{j} \lambda_{j}$ is the same for every victimisation profile. A population with $k$ groups has $2 k$ parameters and three restrictions, giving $2 k-3$ free parameters to determine for each of the different profiles.

Simulating different victimisation profiles. Populations with $k$ $=3$ groups and two random variables, $a$ and $b$ are considered, such that $0<a<b<1$ and the size of the group $1, N_{1}=a N$ and the size of the group 2, $N_{2}=(b-a) N$ are assigned, so that the size of group $3, N_{3}=(1-b) N$ is fixed. Although more groups could be taken into account, this would not give a more general result in terms of different profiles or the concentration of crime. For the crime rates, two further random variables $\alpha$ and $\beta$ are considered, such that $0<\alpha<\beta$, and the crime rates $\lambda_{2}=\kappa \alpha$ and $\lambda_{3}=\kappa \beta$, are assigned, where

$$
\kappa=\frac{C}{N(\alpha(b-a)+\beta(1-b))}
$$

is a fixed parameter which ensures that all the populations have the same (expected) number of crimes $C$. Under these assumptions, group 3 suffers $\beta / \alpha$ times more crime than group 2 and group 1 suffers no crime.

By taking different values of $a, b, \alpha$ and $\beta$, different scenarios under which crime could be distributed among the population are considered. The case of a high concentration of crime (RECC close to one) is obtained either as the result of a large size for the immune population (large $a$ ) or a small size of the most victimised group $((1-b)$ small) with a large crime rate (large $\beta)$.
The case of a small concentration of crime (RECC close to zero) is obtained either as a large size of the most victimised group $((1-b)$ large) and other scenarios (Fig. 1).

Measuring social interactions. Interactions between individuals from different groups might be highly frequent or rare (Newman, 2003). Importantly, the degree of mixing between groups has an impact on the mean fear of crime in the population. Given $N$ members in the population, then the probability that two randomly selected individuals belong to a different group, $\pi$, is given by

$$
\pi=\frac{N^{2}-\sum_{j=1}^{k} N_{j}^{2}}{N(N-1)} .
$$

A metric for the degree of mixing between groups, $\phi$, is given by

$$
\phi=\frac{\eta}{\pi}
$$

where $\eta$ is the proportion between the observed number of interactions which occurred between members of different groups and the number of total interactions. Thus, a value of $\phi>1$ means that interactions happened more frequently between members of different groups than randomness would suggest (thus, a high level of mixing between different groups exist) whereas $\phi<1$ means that interactions occurred more frequently between individuals from the same groups (thus, there is a poor level of mixing between different groups). The extreme case of $\phi=0$ would correspond to the case when individuals only interact with members of their own group. Finally, the case in which $\phi=1$ means random mixing between different groups (Fig. 2).

\section{Simulating different crime dynamics}

Firstly, a victimisation profile for $N=10,000$ individuals or agents is obtained, since this can be viewed as an agent-based model, who collectively expect to suffer $C=1000$ crimes each year. At time $t=0$ individuals have a random fear of crime $s_{i}(0)$ and the same dynamics are simulated for 312 weeks (6 years) and consider only the last 208 (4 years), so that the impact of the random initial fear is diminished (Hegselmann and Krause, 2002).

The simulated individuals have $\gamma=1000$ binary interactions each week, with $\mu=0.1$ and $v=0.9$, so that the impact of the more fearful person is much stronger than the impact of the less fearful person. 


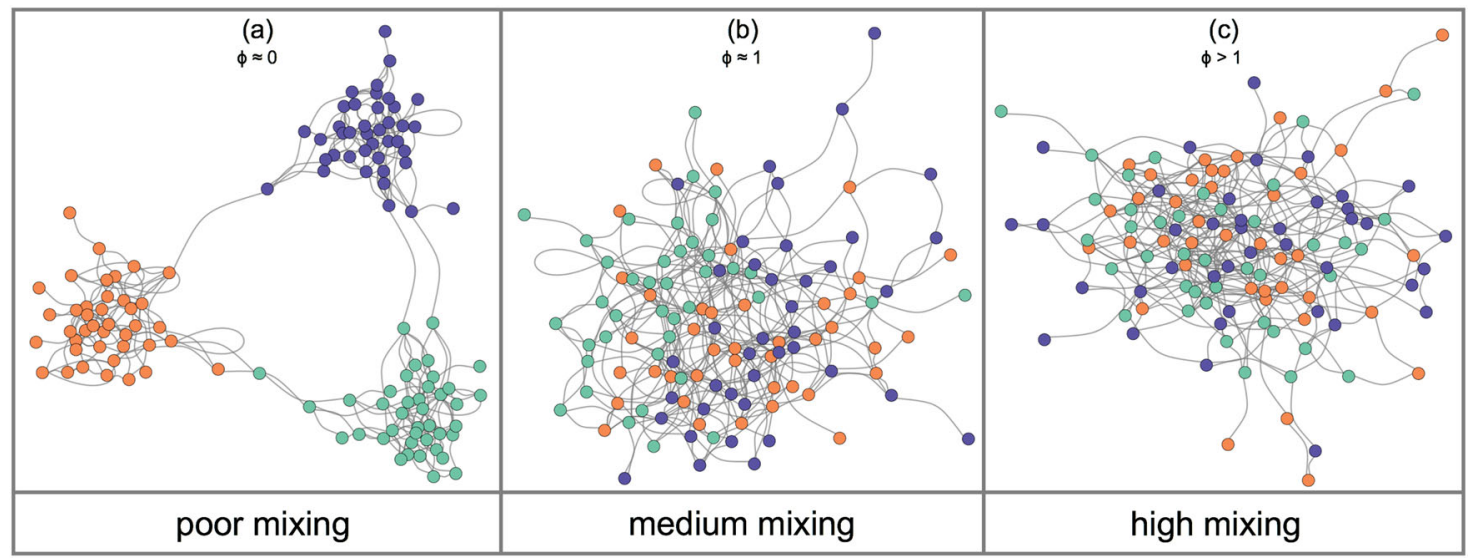

Fig. 2 Different interactions between individuals from different groups. Panel (a) shows individuals who interact mostly with people form their own group (so $\phi \approx 0$ ). Panel $(\mathbf{b})$ shows random interactions and panel (c) shows the case of high mixing, in which individuals interact mostly with people from other groups (so $\phi>1$ )

The impact of memory decay is chosen so that an individual loses half of their level of perception from 1 year to the next, that is, the parameter $\psi$ is chosen such that $s_{i}(52)=\psi^{52} s_{i}(0)=(1 / 2) s_{i}$ (0), so that each week, the parameter for the memory decay is $\psi$ $=0.9867$, meaning that a person has $1.33 \%$ less fear than the previous week. Although most of the emotional effects of suffering a crime might 'wear off within a few weeks or months, the impact can last much longer (Skogan, 1987) and so other values of $\psi$ could be considered (for instance, for different types of crime). In general, a smaller value of $\psi$ means a faster memory decay which leads to less fearful groups and vice-versa for higher values of $\psi$.

Although other values for $\psi$, as well as other values of $v$ and $\mu$, would change the quantitative results, these would not change the qualitative results of the model and with any reasonable values of $\psi$ and the other parameters, simulations help show the emergence of the same patterns.

\section{Results}

Simulating 1000 different victimisation profiles and then, for each, establishing the subsequent dynamics, allows to determine the impact that a higher or lower concentration of crime has on the mean fear of crime within a population. For each simulation, the mean perception of fear from the population $\bar{s}$, the corresponding degree of concentration of crime, the RECC, and the degree of mixing between groups, $\phi$ are obtained. Although the fear of crime of individuals changes from one week to the next, the mean perception eventually has only small fluctuations around its mean and so, on average, a consensus is reached (Toscani, 2006).

The parameters $\mu$ and $v$, which describe the impact of social interactions, is such that higher values of $v$ (the impact of the more fearful person) increase the generalised fear of crime in the simulations, whilst higher values of $\mu$, which means a higher impact from the least fearful person, reduce it.

Most of the individuals do not suffer a crime each year (since the global crime rate is such that for every 100 individuals there are 10 crimes) which means that most of the fear of crime actually comes from social interactions. Thus, the impact of $\gamma$, which considers the frequency of social interactions, is such that more social interactions (higher value of $\gamma$ ) tend to increase the global fear of crime and, in some cases, only if the individual suffers extreme high crime rates, a higher level of social interactions will reduce the average fear from their group (but not the average from the whole population). Less social interactions are always related to a lower fear of crime.
Considering random interactions between individuals from different groups, results show the dynamical behaviour falls into one of two different phases. For low concentrations of crime $($ RECC $<0.5)$ the impact of different degrees of concentration of crime is negligible. There is a phase transition at high degrees of concentration of crime after which, a slight increase in the concentration has a considerable decrease in the general fear of crime.

There is a phase transition (observed for values of the RECC between 0.85 and 0.9 ) for which the impact of a higher or lower concentration of crime becomes highly relevant. For high levels of concentration of crime, an even higher concentration reduces the mean fear of crime of the population (Fig. 3).

Interactions between different groups. The degree of mixing between individuals from different groups changes the impact of the concentration of crime.

When interactions between different groups are not frequent (corresponding to a lower value of $\phi$ ) then the concentration of crime has a significant impact (Fig. 4). With random interactions between individuals from different groups $(\phi=1)$ the concentration of crime still has an impact but only at very high concentrations of crime, and this impact is due to the fact that suffering an actual crime is less significant (that is, there is a smaller change in the mean fear of the population) if the person is highly fearful. When groups are highly mixed $(\phi>1)$, which in turn means that interactions between individuals from the same group are less frequent, then people who suffer crime are more likely to interact with individuals who never suffer crime, increasing the mean fear of crime as a result.

\section{Conclusions}

In terms of the crime suffered by an individual, it is worth noting that a person might suffer more than one crime during the time interval being considered, so that a binary model, dividing victims and non-victims does not apply. Also, there is a random element to the number of crimes suffered and so, even when an individual has a high/low risk of suffering a crime, they might instead experience a small/high number of crimes simply by chance. Assuming a Poisson distribution for the number of crimes suffered by an individual has some disadvantages, for instance, the number of crimes suffered by some individuals might be correlated, but the distribution takes into account a random component and so, for example, an individual with a rate $\lambda=1$, which means that they expect to suffer one crime per year, has, in fact, a 


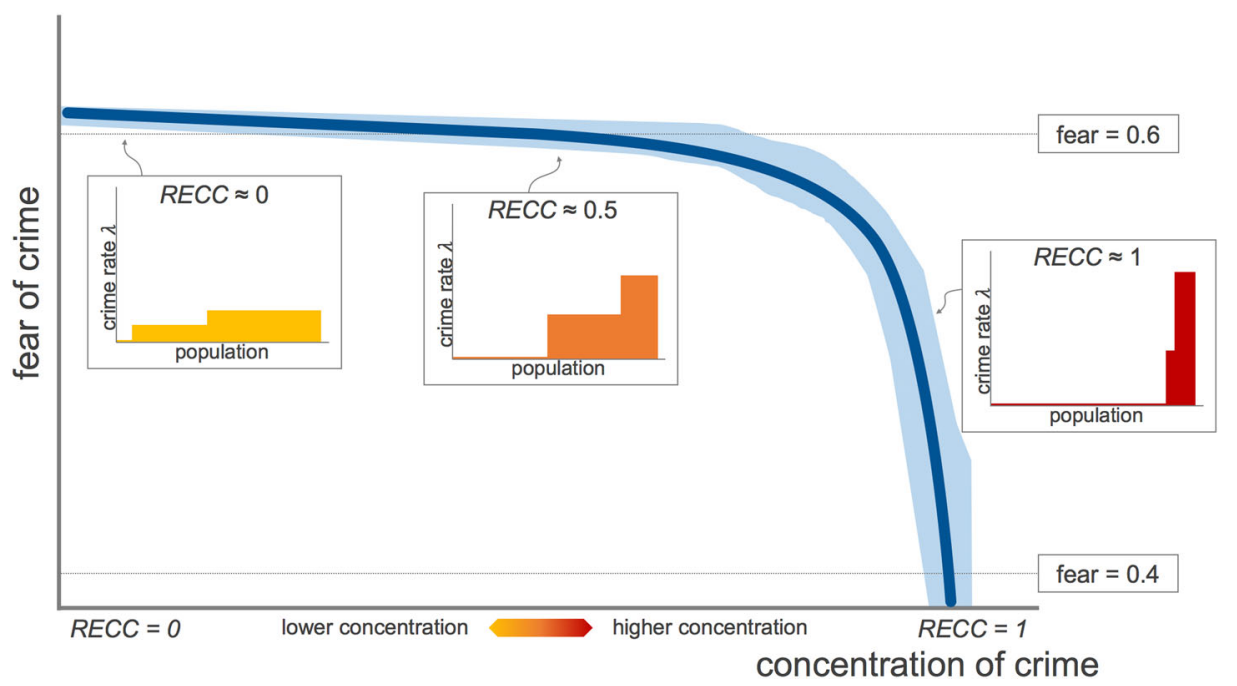

Fig. 3 Impact of the concentration of crime on the fear of crime. Interactions between individuals from different groups are slightly less frequent than in a random model (with an average $\phi=0.8$ ). The mean fear of crime for different victimisation profiles (solid blue line) and the $95 \%$ (in light blue) as the degree of concentration of crime varies. For a small or medium level for the concentration of crime, the impact of different victimisation profiles and therefore, the impact of the concentration of crime, is negligible

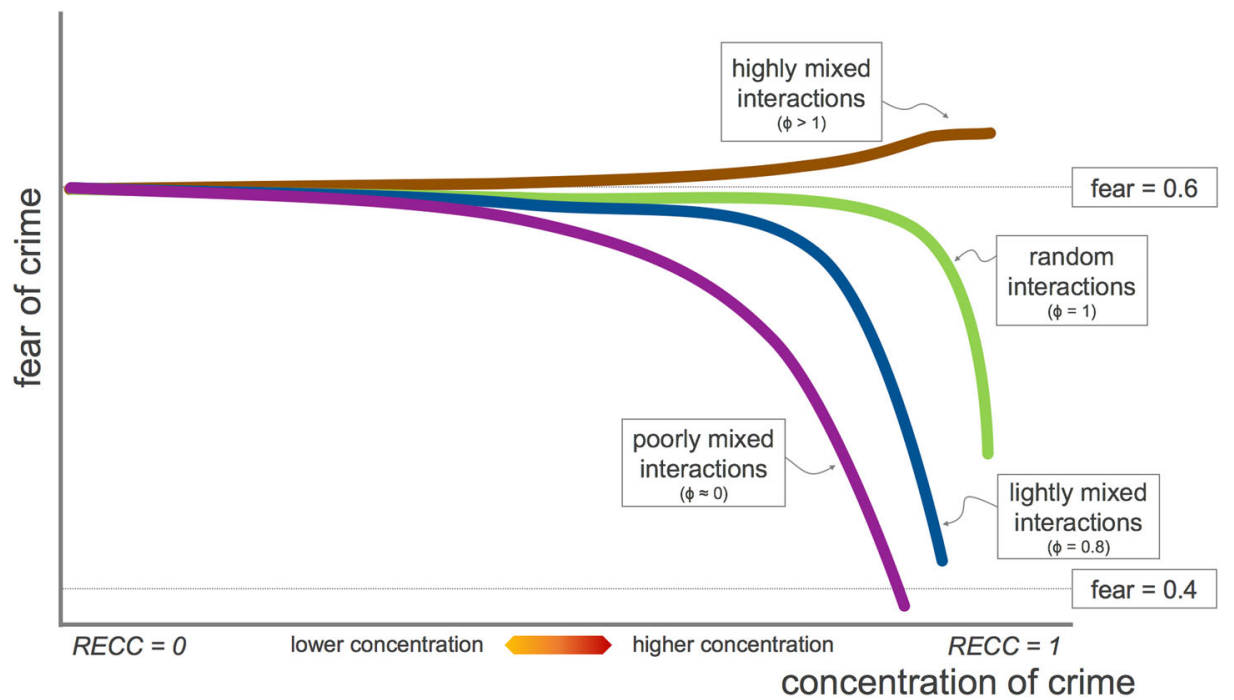

Fig. 4 Impact of the concentration of crime on the fear of crime according to the degree of mixing between individuals from different groups. The victimisation profile effects the mean fear of crime on the population, but the impact changes according to the level of interactions between groups. When individuals from different groups have less frequent interactions (corresponding to a value of $\phi \approx 0$ ) the fear of crime decreases considerably with medium and higher concentrations of crime. With random interactions between different groups (a value of $\phi$ close to one) a higher concentration of crime leads to a decrease in the mean fear of crime. With highly mixed groups ( $\phi$ larger than one) a higher concentration of crime increases the mean fear for the population

0.368 probability of suffering no crimes and a 0.264 probability of suffering more than one crime.

Assuming a Poisson distribution for the number of crimes suffered by a person also allows us to consider distinct rates for different individuals or groups of individuals. The methodology presented here provides a way to consider different distributions of crime in a population and its relation to the fear of crime while keeping the expected number of crimes suffered by the whole population, constant. Thus, it provides a methodology to simulate different distributions of crime, which take into account an immune population group and the fact that crime is, in general, rare and highly concentrated.

In terms of the fear of crime experienced by individuals, the model is a simplification of a much more complex set of social circumstances. However, it captures the three relevant and perhaps most obvious elements which have a clear impact on the fear of crime: suffering a crime, sharing experiences with others and having decay of memory of previous opinions and experiences.

The main contribution here is that the impact of the concentration of crime and its impact on the generalised fear of crime can be analysed. In general, when individuals are more likely to interact with members of their own group, with a higher concentration of crime the fear of crime can drop significantly. People become segregated in many ways and for many reasons (for instance, age, religion, income or even the region of the city in which a group usually inhabits) (Schelling, 1971) and so, the interactions between individuals from different groups are often difficult, for example, people from a run-down neighbourhood 
might have only a few interactions with individuals from a more upmarket community. Results shown here indicate that, in general, for poorly mixed groups, which experience a limited amount of interactions with individuals from other groups, a higher concentration of crime also means a reduced fear of crime.

Another implication of the findings is that this research goes beyond a simple change in parameters allowing us to understand the impact of a common phenomenon observed in different crime strategies, namely the displacement of crime. Unfortunately, some strategies oriented to prevent crime result in some type crime displacement (either the perpetrator chooses different locations, types of crime, modus operandi, or victims). That is, due to a policy oriented to reduce crime, different individuals become the victims of crime (Bowers and Johnson, 2003). Although crime displacement (and in particular victim displacement) is difficult to quantify, this work shows the potential result that a policy oriented to reduce crime might have. Whilst a policy could effectively reduce the number of crimes suffered by the whole population, if some degree of victim displacement is observed, then the chances are that the same policy also creates, at the same time, a more fearful population.

Although it is not necessarily a palatable policy, results indicate that one way to improve the perception of security of a place is to increase the concentration of crime, that is, having a small population group which suffers the majority of the crimes. Results of the simulations show that two populations might suffer the same number of crimes, might have the same type of interactions and dynamics, but one of the groups might have a much lower fear of crime only as a result of a higher concentration of crime.

Frequently, fear of crime is assumed to be only as a direct consequence of suffering crime and thus, by lowering the levels of crime, fear will consequently also be reduced. However, this might not be the case. Fear of crime is a problem in its own right, with costly and long-lasting consequences to the social life of a city and therefore, understanding its causes and the reasons why it emerges as a social phenomenon plays a key role in the correct design of policies.

The findings indicated here provide a theoretical explanation as to why, when viewing crime and its fear, complex behaviour sometimes emerges. For instance, people who are immune to suffering crime still fear it; a higher concentration of crime reduces the generalised fear; the perception that a location is secure might rapidly change. From a global perspective, it is possible to obtain quantitative and qualitative results for the fear of crime and its dynamics. But from an individual perspective, we cannot say much regarding why a specific person has a fear of crime. If a person has a fear of crime of 0.7 , with no additional information, we cannot establish whether that number is the result of a past crime or a recent interaction with a fearful person. Furthermore, we do not know which group that the individual belongs to, and so we do not know if she or he is more fearful than others in that group or perhaps, or whether their fear of 0.7 is as would be expected. The model here indicates the emergence of a social behaviour but not specific aspects of its individuals.

The quantitative part of the model presented here has, admittedly, some limitations in terms of a real-world observation to support the findings. There are also other ways in which the model could be configured, for instance, it is possible that the population could be separated into more than the three groups assumed here or the population could also be arranged into groups distinct by age, occupation or the neighbourhood in which they live. In this work, the yearly crime rate for all individuals is assumed to be constant and at the same rate for all members of each group, but this is clearly an oversimplification of the way in which people suffer crime. It is also assumed that individuals have a constant probability of having some form of social interaction with others and that they share their fear of crime and we assumed the same (asymmetric) impact for all interactions, but again, society and social interactions are far more complicated than this. Thus, in terms of the quantitative measures, the simulations currently have little value for typical real-world applications and cannot be used to predict trends or forecast fear of crime as they stand. However, the qualitative aspects of the model are useful to explain the mismatch between crime and its fear and provide insights into why people who never suffer crime might still fear it. Additionally, the model shows that by changing the distribution of crime, but not the total number of crimes, the mean fear of crime can drastically change.

Beyond fear of crime, similar ideas could be applied elsewhere to help understand public opinions in different situations. For instance, towards international migration, whereby migrants moving to a limited number of cities might experience a different level of acceptance than the same number of migrants who are more evenly distributed over all the cities of a country; or in respect to the use of firearms, where a major event, such as a school shooting, might rapidly change the popularity of a gun policy before slowly decaying back to initial levels. In these and other cases, the model may be able to shed light on the way in which attitudes become heightened and social and cultural aspects which affect the opinion dynamics.

Received: 3 January 2018 Accepted: 19 March 2018

Published online: 17 April 2018

\section{References}

Austin M, Furr A, Spine M (2002) The effects of neighborhood conditions on perceptions of safety. J Crim Justice 30(1):417-427

Becker GS (1968) Crime and punishment: an economic approach. In: The economic dimensions of crime. Palgrave Macmillan, London, pp 13-68

Borooah VK, Carcach CA (1997) Crime and fear, evidence from Australia. Br J Criminol 37(4):635-657

Bowers KJ, Johnson SD (2003) Measuring the geographical displacement and diffusion of benefit effects of crime prevention activity. J Quant Criminol 19 (3):275-301

Box S, Hale C, Andrews G (1988) Explaining fear of crime. Br J Criminol 28 (3):340-356

Brantingham P, Brantingham P (2010) Criminality of place. Eur J Crim Policy Res $3(3): 5-26$

Brunton-Smith I, Sturgis P (2011) Do neighborhoods generate fear of crime? an empirical test using the British Crime Survey. Criminology 49(2):331-369

Carro D, Valera S, Vidal T (2010) Perceived insecurity in the public space: personal, social and environmental variables. Qual Quant 44(2):303-314

Chadee D, Ditton J (2005) Fear of crime and the media: assessing the lack of relationship. Crime, Media, Cult 1(3):322-332

Davies TP, Fry HM, Wilson AG, Bishop SR (2013) A mathematical model of the London riots and their policing. Sci Rep 3:1303

Ditton J, Chadee D, Farrall S, Gilchrist E, Bannister J (2004) From imitation to intimidation a note on the curious and changing relationship between the media, crime and fear of crime. Br J Criminol 44(4):595-610

Dorfman R (1979) A formula for the Gini coefficient. Rev Econ Stat 146-149.

D’Orsogna MR, Perc M (2015) Statistical physics of crime: a review. Phys Life Rev $12: 1-21$

Farrall S, Bannister J, Ditton J, Gilchrist E (2000) Social psychology and the fear of crime. Br J Criminol 40(3):399-413

Farrell G (2015) Crime concentration theory. Crime Prev Community Saf 17 (4):233-248

Farrell G, Pease K (1993) Once bitten, twice bitten: repeat victimization and its implications for crime prevention. Police Res Group 46(1):1-32

Gilchrist E, Bannister J, Ditton J, Farrall S (1998) Women and the 'fear of crime' challenging the accepted stereotype. Br J Criminol 38(2):283-298

Glaeser EL, Sacerdote B, Scheinkman JA (1995) Crime and social interactions. Technical report, National Bureau of Economic Research, Harvard, USA

Gordon MB (2010) A random walk in the literature on criminality: a partial and critical view on some statistical analyses and modelling approaches. Eur J Appl Math 21(4-5):283-306

Grogger J, Weatherford S (1995) Crime, policing and the perception of neighborhood safety. Political Geogr 14(6/7):521-541 
Hale C, Pack P, Salked J (1994) The structural determinants of fear of crime: an analysis using census and crime survey data from England and Wales. Int Rev Vict 3(3):211-233

Heath L, Gilbert K (1996) Mass media and fear of crime. Am Behav Sci 39 (4):379-386

Hegselmann R, Krause U (2002) Opinion dynamics and bounded confidence models, analysis, and simulation. J Artif Soc Soc Simul 5(3):1-33

Helbing D, Brockmann D, Chadefaux T, Donnay K, Blanke U, Woolley-Meza O, Mous- said M, Johansson A, Krause J, Schutte S, Perc M (2015) Saving human lives: what complexity science and information systems can contribute. J Stat Phys 158(3):735-781

Hollis ME, Downey S, del Carmen A, Dobbs RR (2017) The relationship between media portrayals and crime: perceptions of fear of crime among citizens. Crime Prev Commun Saf 19(1):46-60

Hope T, Trickett A (2008) The distribution of crime victimisation in the population. Int Rev Vict 15(1):37-58

Jackson J, Gray E (2010) Functional fear and public insecurities about crime. Br J Criminol 50(1):1-22

Johnson SD (2010) A brief history of the analysis of crime concentration. Eur J Appl Math 21(1):349-370

Kleck G, Barnes J (2014) Do more police lead to more crime deterrence? Crime Delinq 60(5):716-738

Lane J, Meeker JW (2003) Ethnicity, information sources, and fear of crime. Deviant Behav 24(1):1-26

Latané B (1981) The psychology of social impact. Am Psychol 36(4):343

Morgan P (1978) Delinquent fantasies.. Temple Smith, London

Newman ME (2003) The structure and function of complex networks. SIAM Rev 45(2):167-256

Pantazis C (2000) Fear of crime, vulnerability and poverty. Evidence from the British Crime Survey. Br J Criminol 40(1):414-436

Pease K (1998) Repeat victimisation: taking stock. Home Office Police Research Group London, UK

Prieto Curiel R, Bishop SR (2016a) A measure of the concentration of rare events. Scientific Reports 6:32369

Prieto Curiel R, Bishop SR (2016b) A metric of the difference between perception of security and victimisation rates Crime Sci 5(1):1-15

Prieto Curiel R, Bishop SR (2017) Modelling the fear of crime Proc Royal Soc London A 473(2203):1-14

Prieto Curiel R, Collignon Delmar S, Bishop SR (2017) Measuring the distribution of crime and its concentration. J Quant Criminol 1-29. https://link.springer. com/article/10.1007/s10940-017-9354-9

Ruijsbroek A, Droomers M, Groenewegen PP, Hardyns W, Stronks K (2015) Social safety, self-rated general health and physical activity: changes in area crime, area safety feelings and the role of social cohesion. Health Place 31:39-45

Sacco VF (1993) Social support and the fear of crime. Canadian Journal of Criminology 35:187

Schelling TC (1971) Dynamic models of segregation. J Math Sociol 1(2): $143-186$

Short M, Brantingham J, Bertozzi A, Tita G (2010) Dissipation and displacement of hotspots in reaction-diffusion models of crime. Proc Natl Acad Sci 107 (1):3961-3965
Skogan WG (1987) The impact of victimization on fear. Crime Deling 33 (1):135-154

Skogan WG, Maxfield MG (1981) Coping with crime: individual and neighborhood reactions. Sage Publications, Beverly Hills, CA, p 272

Sparks RF (1981) Multiple victimization: evidence, theory, and future research. J Crim Law Criminol 72(2):762-778

Toscani G (2006) Kinetic models of opinion formation. Commun Math Sci 4 (3):481-496

Tseloni A (2007) Fear of crime, perceived disorders and property crime: a multivariate analysis at the area level. Crime Prev Stud 21:163-185

Tseloni A, Mailley J, Farrell G, Tilley N (2010) Exploring the international decline in crime rates. Eur J Criminol 7(5):375-394

\section{Data availability}

Data sharing is not applicable to this article as no datasets were generated or analysed during the current study.

\section{Acknowledgements}

RPC acknowledges the support the government of Mexico via a Conacyt Scholar.

\section{Author contributions}

RPC designed the study and processed the data; RPC and SRB analysed the results; both authors wrote the paper.

\section{Additional information}

Competing interests: The authors declare no competing interests.

Reprints and permission information is available online at http://www.nature.com/ reprints

Publisher's note: Springer Nature remains neutral with regard to jurisdictional claims in published maps and institutional affiliations.

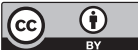

Open Access This article is licensed under a Creative Commons Attribution 4.0 International License, which permits use, sharing, adaptation, distribution and reproduction in any medium or format, as long as you give appropriate credit to the original author(s) and the source, provide a link to the Creative Commons license, and indicate if changes were made. The images or other third party material in this article are included in the article's Creative Commons license, unless indicated otherwise in a credit line to the material. If material is not included in the article's Creative Commons license and your intended use is not permitted by statutory regulation or exceeds the permitted use, you will need to obtain permission directly from the copyright holder. To view a copy of this license, visit http://creativecommons.org/ licenses/by/4.0/

(C) The Author(s) 2018 